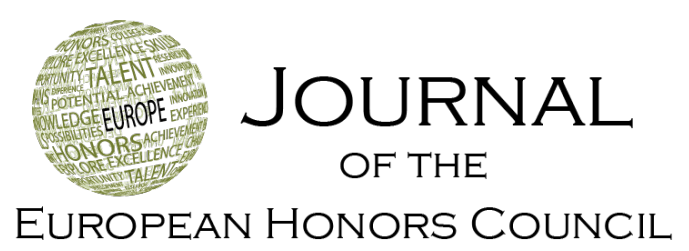

Note

\title{
The role of honors teaching assistants as community builders
}

\author{
Meghan Grassel, Hanna Holmquist, and Rebecca C. Bott-Knutson*
}

Van D. And Barbara B. Fishback Honors College at South Dakota State University; meghan.schenk@jacks.sdstate.edu; hanna.holmquist@sdstate.edu; rebecca.bott@sdstate.edu

Correspondence: rebecca.bott@sdstate.edu

Received: 9 August 2019; Accepted: 11 September 2019; Published: 27 October 2019

\begin{abstract}
Within the Van D. and Barbara B. Fishback Honors College at South Dakota State University (SDSU), undergraduate teaching assistants (TAs) mentor small groups of students in our first-year Honors Orientation classes. These near-peer guided small groups simulate the benefits of smaller classes within larger sections and promote relationship building within honors. To assess the value of having teaching assistants in these classes, we surveyed both the students enrolled in Honors Orientation as well as the undergraduate TAs. Students felt that relationships, academic support, and smaller group sizes were benefits of TAs in the classroom. The TAs believed the relationships they formed with other students were the primary benefit to their experiences, along with growth in teaching and mentoring skills. These results indicate our teaching assistants are important connections between firstyear students and the Fishback Honors College.
\end{abstract}

Keywords: Honors education, community, teaching assistant, first-year experience

\section{Introduction}

Small classes are known to increase involvement, academic performance, and satisfaction for students (Donahue, 2004). Additionally, connections to other students are important for student success within honors and the university as a whole (Donahue, 2004). The incorporation of undergraduate teaching assistants (TAs) into the honors classroom brings value for both the students enrolled in the course as well as the TAs. Smaller class sizes are undeniably better for student learning and experience (Beattie \& Thiele, 2016). However, large class sizes are a necessity for many first-year courses given time and budget constraints. The integration of TAs mitigates some of the limitations of large class sections by mentoring students through the transition to college and facilitating community building in the course. Additionally, the TAs benefit from the experience through developing 
mentoring and teaching skills. Overall, the utilization of TAs in large, introductory courses can greatly benefit students, TAs, and honors programs.

First-year students' ability to form connections is crucial for their retention to the university, as well as persistence within an honors college or program (Donahue, 2004). Thus, the importance of building community within first-year courses cannot be understated. Creating opportunities for students to make connections within their communities should be a priority for honors colleges (Johnson, 2009). In some college courses, TAs help build community among students by facilitating interactions among groups of peers, integrating academic support, and promoting opportunities for out-of-class engagement. Student learning and satisfaction greatly increase with the incorporation of a TA in the classroom, and this increased student interaction is also known to increase student learning (Johnson, 2009). So, TAs can help create classroom environments conducive to learning and community building. There are also benefits for students who serve as TAs. Peer teaching has psychological benefits, such as increased learning ability and a more positive connection to campus (Terrion, 2013). The learning process becomes bi-directional; when the TAs teach the material, it gives them a deeper understanding of the lessons. Additionally, Terrion (2013) stated that the TAs have increased networking opportunities, which can contribute to a positive experience at the university. Thus, it stands to reason that utilizing TAs in honors courses could lead to a more positive experience for TAs within the honors college through deeper relationships, learning, and leadership experiences.

\section{Methods}

The Honors Orientation course for first-year students at SDSU is designed as an introduction to the Fishback Honors College student experience. It is a one-credit, semester-long course built around themes of ethics, diversity, and empowerment and includes practical examination of integrating the honors experience within academic and co-curricular programs. Assignments cover requirements and tenants of the honors experience, such as coursework, service, and undergraduate research. Additionally, students are introduced to opportunities such as study abroad and campus involvement.

Each section of Honors Orientation has between 50 and 90 first-year students enrolled, and there were four sections of the class offered in the 2018 fall semester. Instructional methods include lectures, guest speakers, discussions, and group work. The honors dean and honors advisor co-teach all sections of the course along with the current honors students who serve as TAs. First-year students who enroll in the class are organized into small groups of about ten students led by one TA.

Twenty-nine students served as TAs during the semester of study. These TAs were sophomore, junior, and senior honors students from a variety of majors. TAs attended each meeting of the Honors Orientation class, where they led small group discussions and contributed to class presentations. The TAs also did some grading and attended out-of-class meetings and events. TAs participated in a half-day training before the start of the semester to prepare for their experience. The course instructors led this training and guided TAs through expectations and responsibilities for their role. It also introduced TAs to potential pitfalls, such as struggling students or grade disputes, tactics to overcome those challenges, and when to seek help from the instructors. TAs were further briefed on campus FERPA, Title 
$\mathrm{IX}$, and EO policies so that they would be familiar with protocols and how to maintain privacy and provide support in accordance with our institutional and federal requirements. TAs were also coached in creating goals for themselves and goals for their first-year students. At weekly meetings throughout the semester, TAs had opportunities to interact with the course instructors and fellow TAs to ask questions, share ideas, disclose progress on goals, and prepare for class presentations and discussions.

This study utilized both survey and interview techniques. An anonymous, online survey was developed and distributed via e-mail to all students enrolled in the Honors Orientation course at the conclusion of the fall 2018 semester. Students were asked to respond to the following questions, and responses were analyzed for similar themes by the researchers:

1. What were the most rewarding and/or beneficial things for you about having Teaching Assistants (TAs) in Honors Orientation?

2. In what ways could we develop the TA role to make the TAs an even more positive part of your Honors Orientation experience?

TAs who served in the Honors Orientation class during the previous semester were interviewed face-to-face by one of the researchers and asked about the most rewarding and challenging parts of their experience. TA responses were recorded during the interviews without identifying information. These responses were compiled and reviewed for common themes both among TAs and compared to the general themes of responses from our firstyear students. Both elements of the study were approved by the Institutional Review Board.

\section{Results}

\section{First-year student responses}

The survey to first-year students yielded a $23 \%$ response rate with 55 out of 242 students completing the survey. The themes that emerged from the first-year students' responses about the benefits of working with TAs were mentorship support, smaller groups within the class, and academic support. The primary benefit reported by $71 \%$ of first-year students $(n=39)$ was the mentorship they gained from the TAs. One student remarked, "It was really beneficial to have yet another friend/support here at SDSU as new members of the SDSU community." The second benefit reported by $29 \%$ of first-year students $(n=16)$ was academic support. The first-year students felt their TAs helped them navigate the transition to college in their respective majors and within honors. Smaller group size within the class was also mentioned by $20 \%$ of the first-year students $(n=11)$ as a benefit of having TAs in the course.

First-year students were also asked what could be improved about the ways TAs are utilized in the Honors Orientation course (Figure 1). Of the first-year students surveyed, $40 \%(n=22)$ provided no suggestions for improvement. $18 \%$ of students $(n=10)$ felt that even smaller groups within the class would improve their experience. $15 \%$ of students $(n=8)$ mentioned that having a TA who had the same major as them would have been an improvement, and the same number of students felt that more interactive activities within the TA groups would improve the experience. Having more opportunities to interact with all of the TAs and changes to grading processes were also mentioned as suggestions for improvement. 


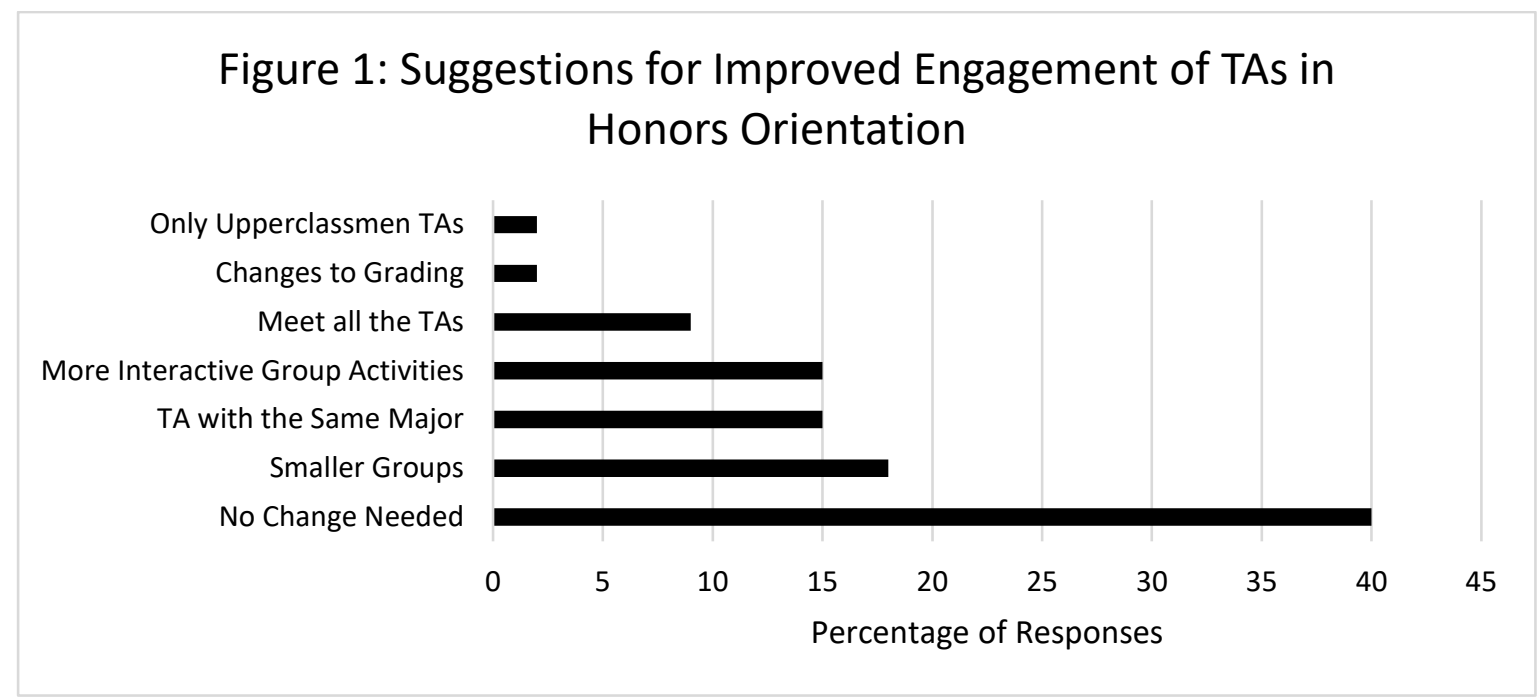

\section{Teaching assistant responses}

During interviews, TAs mentioned that they had future activities planned with students in their group. This indicates that TAs develop long-lasting relationships with their students, which helps keep students connected to the honors community beyond their first semester. TAs also said there was value in being placed in groups with students of a similar academic focus. TAs who were in groups where their students had the same major were able to share their academic experiences beyond honors and offer advice for rewarding academic experiences that were more relevant to their students. TAs remarked that the most rewarding part of the experience was seeing their students engage more broadly on campus. TAs were challenged in their experience as well. A reported challenge was having a student that was not actively engaging in class activities and discussions. TAs mentioned trying multiple tactics to overcome this challenge and feeling frustrated when the student still did not engage. Additionally, younger TAs found it difficult to give advice about some aspects of honors they had not yet experienced-such as undergraduate research.

While the first-year students expressed the value of TAs in terms of "mentorship" or "small groups," the TAs primarily focused on the value of forging long-lasting relationships. In a sense, both groups are ultimately addressing relationships and community. First-year students described the relationships at a micro-level, articulating specifics benefits of the relationships, whereas the TAs discussed relationships and the sharing of resources from a more global view.

\section{Implications}

TAs add value for first-year students through mentorship, academic support, and creating smaller groups within larger classes. The students who act as TAs also benefit from serving as mentors and developing connections with their students that extended beyond the classroom. For first-year students, building connections is integral to success at college and within honors (Donahue, 2004). TAs offer valuable academic support for first-year students, and they also serve as mentors and help students build connections within honors. Utilizing TAs in the Honors Orientation classes allows our honors community to flourish, and we believe this is a strategy that can be implemented with similar success in other honors colleges and programs. 
Acknowledgments: We appreciate the tremendous talent and community building efforts of our honors teaching assistants.

\section{References}

Beattie, I. R., \& Thiele, M. (2016). Connecting in class? College class size and inequality in academic social capital. The Journal of Higher Education, 87(3), 332-362.

Donahue, L. (2004). Connections and reflections: Creating a positive learning environment for first year students. Journal of the First-Year Experience \& Students in Transition. 16(1), 77-100.

Johnson, M. (2009). The role of peer leaders in an honors freshman experience course. Honors in Practice, 5, 189-196.

Terrion, J. L. (2013). Student peer mentors as a navigational resource in higher education. In S. J. Fletcher \& C. A. Mullen (Eds.), The SAGE Handbook of Mentoring and Coaching in Education (pp. 383-397). London: SAGE Publications Ltd. 